\title{
Posición de la SMNyCT frente al tabaquismo
}

\author{
Mesa Directiva, SMNyCT 2017-2019凶
}

\section{Estimados socios:}

A partir del año 2015 la Secretaría de Salud a través del CENAPRECE, dio inicio al proceso de implementación del Programa de Acción Específico para la Prevención y Control de Las Enfermedades Respiratorias e Influenza (PAE-ERI), en las 32 entidades federativas, en coordinación con el Instituto Nacional de Enfermedades Respiratorias (INER) y la Sociedad Mexicana de Neumología y Cirugía de Tórax (SMNyCT).

Este Programa de Salud, se encarga de normar la atención médica de dos patologías respiratorias agudas (neumonías e influenza) así como dos enfermedades respiratorias crónicas (asma y EPOC).

Por tal motivo hacemos de su conocimiento algunos datos referentes a la situación actual a nivel internacional y local que tenemos con la EPOC en la población mexicana:

Según estimaciones de la OMS (2004), unos 64 millones de personas sufren una EPOC; en 2012 murieron más de 3 millones de personas por EPOC $(6 \%$ de todas las causas), $90 \%$ en países de bajos y medianos ingresos. Se estima que uno de cada cuatro individuos son propensos a ser diagnosticados por EPOC durante su vida, con incidencias de hasta 19.7\%. Asimismo, la OMS estima que la EPOC se habrá convertido en la tercera causa de muerte en todo el mundo en 2030.

En 2015, México registró oficialmente 24,674 defunciones por EPOC de las cuales 11,436 correspondieron a mujeres y 13,238 a hombres. En los datos del INER, se reporta que la EPOC se ubica en sexto lugar de mortalidad en México y que para el 2020 estará en el $4^{\circ}$ lugar. Es importante destacar que por género los daños a la salud en términos de muertes por EPOC, en la población de mujeres son mayores incluso que los cánceres de mama y CaCu juntos $(10,282)$, en comparación con las muertes en mujeres ocasionadas por la EPOC que ascienden a 11,436. En cuanto a los costos de atención de la EPOC, datos del INER publicados en 2016 reportan que el gasto anual por paciente en etapas tempranas es de 1,169 dólares y en etapas avanzadas se incrementa hasta en 2,306 dólares.

En un análisis de costos del Instituto Mexicano del Seguro Social de 2013, el tratamiento ambulatorio de un episodio de exacerbación (que actualmente es el motivo principal de consulta de los pacientes con esta enfermedad) de EPOC es de $\$ 21,528.93$ pesos y los costos se incrementaban para un manejo hospitalario hasta $\$ 212,962$ pesos.

Haciendo énfasis en algunos datos estadísticos de relevancia de esta enfermedad, encontramos dentro de la literatura científica que la prevalencia de pacientes de EPOC con comorbilidades es la siguiente: diabetes mellitus de $36 \%$, hipertensión arterial hasta $63 \%$, dislipemias $34 \%$, obesidad $29 \%$, cardiopatía isquémica $21 \%$, etc. En este sentido, es de suma importancia mejorar la evidencia de lo que sucede en nuestro país con los daños a la salud ocasionados por este proceso respiratorio obstructivo.

Cabe hacer mención de que los factores de riesgo para que una población desarrolle la enfermedad estriban en el tabaquismo como el factor de riesgo más importante para el desarrollo de las enfermedades de tipo obstructiva de las vías respiratorias y del cáncer pulmonar, otros factores de riesgo como la exposición a biomasa y a polvos, humos y gases en ambientes laborales, en menor proporción son causas directas del desarrollo de la enfermedad en la población mexicana.

Por este motivo nuestra Sociedad ha decidido adoptar como una política la siguiente posición frente al tabaquismo:

I. Se prohíbe fumar en todas las reuniones de negocios, sociales y ceremoniales. La SMNyCT se abstendrá de colaborar con reuniones en las cuales esta regla no sea aceptada y cumplida.

II. La SMNyCT desarrollará, apoyará y participará en programas para educar a los profesionales médicos y al público en general sobre los peligros 
del tabaco para la salud. Los programas dirigidos especialmente a los niños y adultos jóvenes, para evitar el consumo del tabaco son de particular importancia; informando también sobre los daños ocasionados por los productos similares como la pipa de vapor o cigarrillos electrónicos.

III. Los programas de disuasión dirigidos a los no fumadores y a los que no consumen tabaco, son tan necesarios como la educación destinada a convencer a los fumadores que dejen el consumo del tabaco.

IV. Estimulará a cada socio para que sea un modelo de comportamiento (al no consumir tabaco) y portavoz de la campaña para educar al público sobre los efectos nocivos del tabaco para la salud.

V. Participará en iniciativas para convertir a los hospitales, instituciones de salud y educativas en zonas libres de tabaco donde no se consuma, ni se tenga venta de cigarros en sus instalaciones, dando énfasis en las instituciones educativas de cualquier nivel, en especial universidades y centros de estudios superiores.

VI. Rechazará financiamientos de la industria del tabaco y exhortará a las escuelas de medicina, instituciones de investigación e investigadores a hacer lo mismo, a fin de no fomentar la credibilidad ni participar en las llamadas campañas de «responsabilidad social» de esta industria, mientras mantienen una expansión en países en desarrollo y en grupos marginados.

VII. La revista NCT no aceptará trabajos financiados de manera directa o indirecta por la industria del tabaco.

VIII. Ningún socio podrá ser directivo o jefe de sección si ha recibido pagos o regalos, o tiene alguna relación financiera de la industria del tabaco.

IX. Se considera al Convenio Marco de la Organización Mundial de la Salud de lucha contra el tabaco el mecanismo internacional idóneo para el control del tabaquismo, e insiste en su implantación acelerada, inclusive con medidas más estrictas del mínimo propuesto por el convenio.

X. La SMNyCT desaprueba enfáticamente cualquier negociación o convenio con la industria del tabaco que realicen los ministerios de salud, fuera de lo establecido en el Convenio Marco de la OMS.

\section{$\triangle$ Correspondencia:}

Correo electrónico: smnyct.vanessa@gmail.com 